\title{
COVID-19 RE-INFECTION: A CASE REPORT OF A BANGLADESHI DOCTOR
}

\author{
MRINAL SAHA ${ }^{1}$, MOUSUMI DHAR $^{2}$, GOUTAM SAHA ${ }^{2}$
}

Received: 08 November, 2020

Accepted: 25 December, 2020

DOI: https://doi.org/ 10.3329/bjm.v32i1.51096

\begin{abstract}
Introduction
Probably the first coronavirus outbreak was recorded in China on November 17, 2019. It is estimated that at least 266 people were infected with the coronavirus in China last year ${ }^{1}$. Later, it has gradually spread around the world. To date, 43,442,739 people have been infected with the severe acute respiratory syndrome coronavirus 2 (SARS-CoV-2) worldwide and $1,160,487$ people have died. ${ }^{2}$ It has not only been a threat to the global health care but also created considerable psychological complications with all its phenomenal effects. Here, we are going to present a case report of a 38-year-old Bangladeshi doctor who had been re-infected with COVID-19 and the disease was more severe in the second time. There is a huge controversy whether there is any possibility of COVID 19 re-infection or not. The whole world is curious about the antibody level that might develop after COVID-19 infection that might play a role in vaccine development.
\end{abstract}

\section{Case Report}

The patient has been working in the emergency department of a government medical college hospital where he had to work for the COVID patient. Like every day, he completed his duty on 15-07-2020. On the next day he felt chest tightness, fatigue, and palpitation but he did his duty on 16-07-2020. During his duty he felt chest discomfort and did ECG and chest X-ray. Later, on 17-07-2020, he felt nausea and vomiting for which he took some anti-ulecerent and dompiridon tablets. It was observed that his heart rate was average $116 /$ minute with a maximum rate of $130 /$ minute. He found this symptom abnormal and did some necessary blood tests. His blood test report results were almost normal even though he was uncomfortable with his mild shortness of breath and anorexia. On 18-07-20, he developed nausea, restlessness, and palpitation with around $4 \mathrm{~kg}$ of body weight. Then he decided to give a nasal swab for the RT-PCR test for COVID-19 on 19-07-20 and the test report was COVID-19 positive. His saturation of oxygen level was found in between $96 \%$ to $98 \%$ with occasional chest pains. With those sign symptoms, he did an HRCT of the chestOn 23-07-20 that said, "Bilateral Pneumonitis- Bilateral scattered subtle ground glass opacities at both lungs involving all the lobes". Though his ground-glass opacities were mild and scattered in the different zones of both lungs he was having chest tightness. He also observed a little ST-T change in his follow up ECG. He was anxious but no anxiolytic gave him any solution. So, he got admission in a COVID dedicated hospital where he received one course of injectable steroid. He was non diabetic but after intake of steroid his blood sugar level increased. His heart rate was controlled by tablet diltiazem. On 30-07-2020, his second sample for the COVID-19 RT-PCR test was negative which suggests that he had possibly recovered from COVID-19 both clinically and biochemically. He returned home and his diabetes level subsided gradually. From the first week of August 2020, he started his routine hospital work again.

On 29-08-2020, evening he developed running nose and sneezing. He thought it could be allergic rhinitis. But the next day he had severe body ache with fever which was $100^{\circ} \mathrm{F}$. The temperature was going high from time to time. From 30-08-2020 he developed anosmia and severe fatigability. On 31-08-2020, he hadmild cough but his runny nose was subsided. His heart rate was increasing which was intolerable with mild work. Along with this palpitation, he also developed severe anorexia, nausea, and vomiting. He

1. MAG Osmani Medical College Hospital, Sylhet, Bangladesh.

2. Faculty of Science, University of Dhaka, Dhaka-1000, Bangladesh.

Address of Correspondence: Dr. Mrinal Saha, MAG Osmani Medical College Hospital, Sylhet, Bangladesh. Email:2ranamath06@gmail.com

Bangladesh J Medicine 2021; 32 : 58-61 
gave his sample on 01-09-2020 for COVID-19 RTPCR and the report was COVID-19 positive for the second time. About a month after his first attack and full recovery, he was again infected by COVID-19 for the second time. This time the condition was so critical and often his saturation was falling. He tried his best to stay at home with the symptomatic treatment including oral antiviral (Favipiravir) and oral steroid (Dexamethasone). There was no response rather the physical condition was deteriorating especially the fever. He got admitted to the hospital on 04-09-2020 and stayed there for about 2 weeks. During his hospital stay, he had to take $\mathrm{O}_{2}$ inhalation 4 to $6 \mathrm{~L}$ occasionally. He took anti-viral Remdesivir injection for 5 days, Inj Dexamethasone $10 \mathrm{mg}$ IV daily for 5 days then oral $5 \mathrm{mg}$ daily for 5 days. He had weight loss and severe vomiting during his hospital stay however after taking steroid injection; he had regained both appetite and weight. Fever persisted for 9 days with the highest recorded temp of $103^{\circ} \mathrm{F}$ with severe body ache and fatigability. After 15 days of suffering, his condition was a bit improving but palpitation, sleep disturbance, restlessness, and agitation were persisting. He was COVID-19 negative on 16-09-2020 and discharged from the hospital with the advice of HRCT of the chest, Holter monitoring, and Color Doppler Echocardiography. After discharge, he was taking rest at home. On 18-09-2020, he did his HRCT of the chest which revealed, residual $28 \%$ of lungs were still involved with ground-glass opacity involving all zones. His saturation fluctuates from $94 \%$ to $96 \%$.
Often it becomes $90 \%$. His palpitation was getting worsen and frequent heart rate was $110 / \mathrm{min}$ to 112 / min. On $19^{\text {th }}$ September 2020, again developed fever $\left(101^{\circ} \mathrm{F}\right)$ and there was a large painful left-sided submandibular lymph node. Fever subsided soon with paracetamol but the lymph node was bothering him. About one week later he developed burning sensation in his whole body, chest tightness, occasional chest pain, sleep disturbance, severe fatigability. From $30^{\text {th }}$ September he was having restless and anorexia for which he took Escitalopram and Lorazepam according to the psychiatrist. He received another COVID-19 negative report on 03-10-2020. On 6th October, he did his 24 hour holter monitoring which showed supraventricular ectopics, and his heart rate was highest $166 / \mathrm{min}$ and lowest $65 / \mathrm{min}$. He did his echocardiography on 08-10-2020 and there was no wall motion abnormality with mild Pulmonary Hypertension. He was having occasional chest pain and tightness until the second week of October 2020. He was advised to continue Rivaroxaban $10 \mathrm{mg}$ once daily for 3 months along with deltiazem and vitamin B complex. He became anxious with some forgetfulness and low mood. In comparison with two infections, the second one was more severe both in terms of duration and severity. He was a patient of long COVID-19 and still having some minor problems for which he has to compromise his normal lifestyle.

TableI

Results of COVID RT-PCR Test reports:

\begin{tabular}{lll}
\hline Date & Test & Result \\
\hline First time & & \\
$19 / 07 / 2020$ & SARS-COV-2 (RT-PCR) & Positive \\
$30 / 07 / 2020$ & SARS-COV-2 (RT-PCR) & Negative \\
Second time & & \\
$01 / 09 / 2020$ & SARS-COV-2 (RT-PCR) & Positive \\
$16 / 09 / 2020$ & SARS-COV-2 (RT-PCR) & Negative \\
$03 / 10 / 2020$ & SARS-COV-2 (RT-PCR) & Negative \\
\hline
\end{tabular}


Table-II

Results of Test reports:

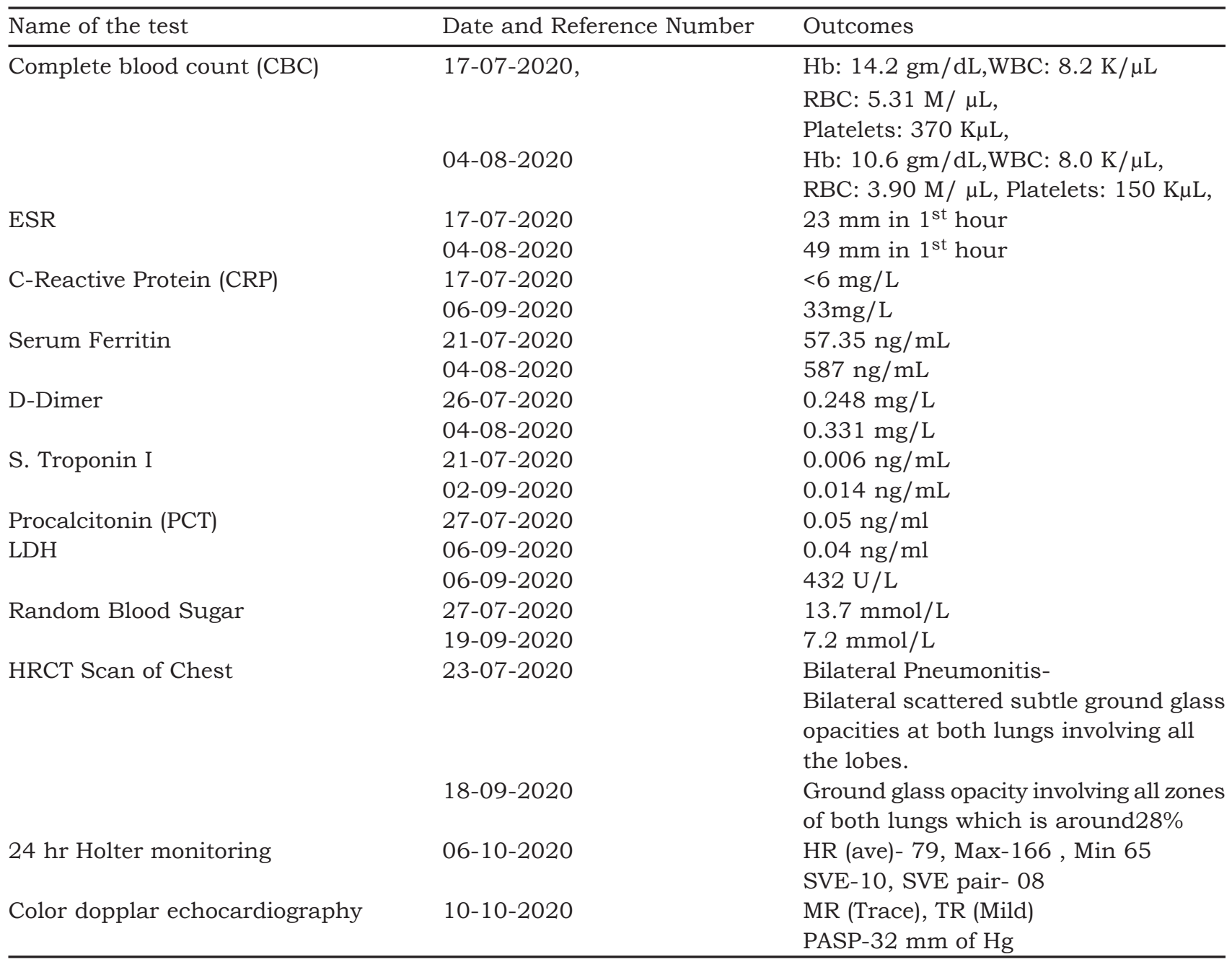

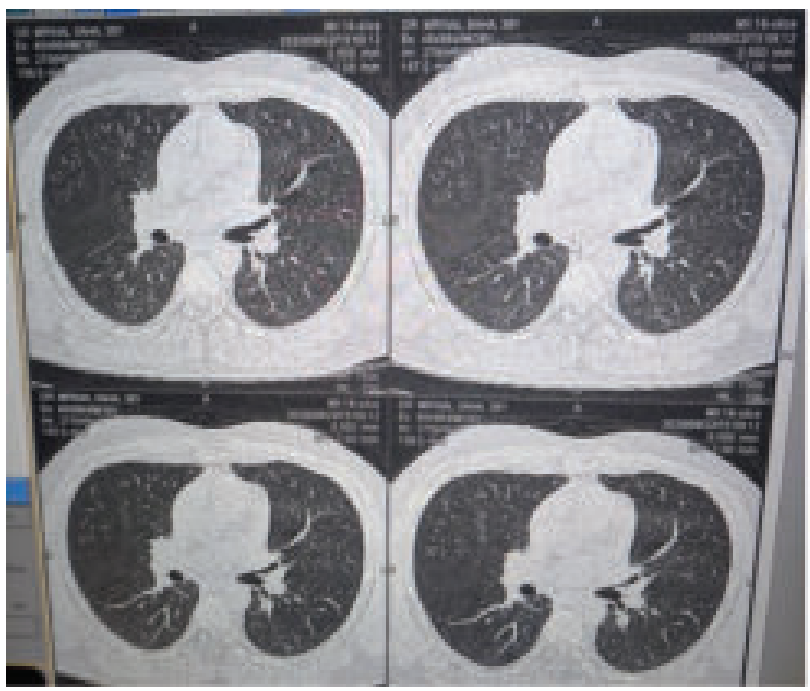

Date: 23-07-2020

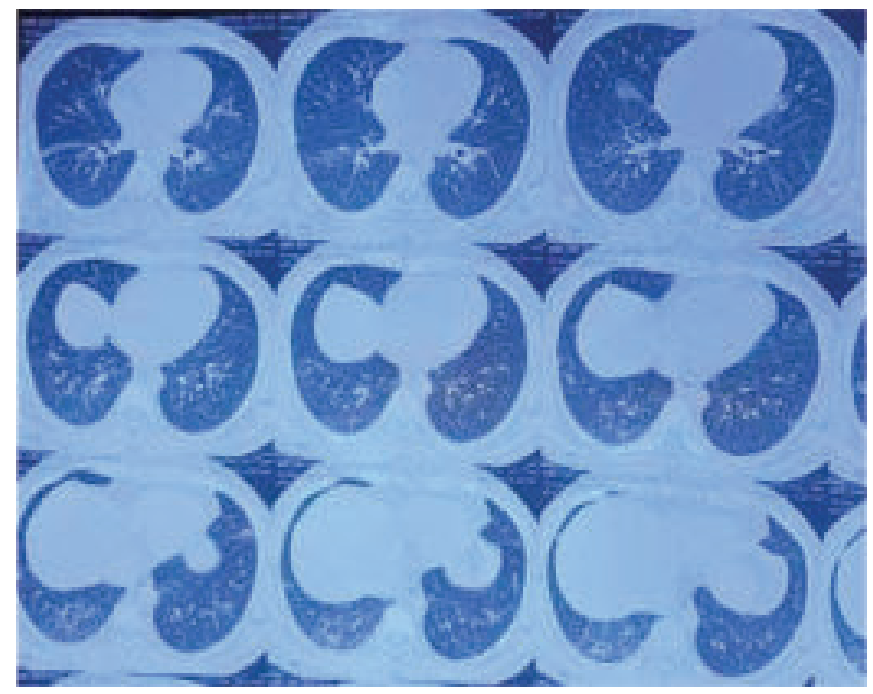

Date: 18-09-2020

Fig.- 1: HRCT SCAN for Chest 


\section{Discussion and Conclusion}

According toWHO, "there is currently no evidence that people who have recovered from COVID-19 and have antibodies are protected from a second infection"[3]. On 23 April 2020, Alizargar reported that 116 COVID-19 recovered patients in South Korea re-infected again [4]. Also, on 26 August 2020, a group of scientists from Hong Kong reported first confirmation of re-infection [5].On August 30, 2020, CGTN published a news report which suggests the first case of COVID-19 re-infection in Ecuador. They also reported two cases of COVID19 re-infection in Nederland and Belgium [6]. Doctors also confirmed first COVID-19 reinfection in USA [7]. From the above information it is evident that a person with COVID-19 can be re-infected with COVID-19. So one should not assume that a person will not be infected for the second time. However, more research is needed in this regard. So everyone has to follow the hygiene rules. Some points which the author observed during this case study:

1. Re-infection is common nowadays, initially which was a myth. So, the chance of a third infectioncould also be a possibility. According to this study if the first infection is mild to moderate then the second infection will be more severe. It is due to the mild host response inless severe cases and development of minimum or no antibody which is alarming for all.

2. It is seen that anosmia may persist up to months and at some point with anosmia the disease prognosis is good. Running nose could be a clinical feature of COVID 19.

3. Persistent fatigability and tachycardia is very common in post-COVID period which takes long time to recover-19. These are very common in reinfection. Cardiac involvement due to COVID-19 is dangerous and have worst outcome.

4. Loneliness and less mental support can make COVID-19 patients more severe. Psychiatric collaboration and counseling could be an important component of post COVID period.

5. Some other similar COVID-19 re-infection cases were found in different medical colleges of Bangladesh but those were not confirmed.
6. There was no study done with asymptomatic career. Most importantly, the COVID-19 antibody test is not available in Bangladesh till now, so the development of herd immunity is still unclear.

7. According to this study, during first infection the patient was infected alone. His family member was not infected. But in re-infection his whole family was affected. Surprisingly, both the time his care giver who share the same room and had active contact tested COVID negative several times. So, it is unclear who could be infected and the detailed mode of transmission of COVID 19.

Acknowledgements: A written consent was obtained from the patient and he provided all the information's that is mentioned in the article.

\section{References}

1. China's first coronavirus case traced back to November 17, 2019. The Business Standard. Link:https:// www.google.com/amp/s/tbsnews.net/international/ coronavirus-chronicle/chinas-first-coronavirus-casetraced-back-november-17-55612\%3famp

2. Covid-19: Coronavirus pandemic. Link: https:// www.worldometers.info/coronavirus/

3. World health Organization: "Immunity passports" in the context of COVID-19 published on 24 April 2020. Link: https: / www.who.int/publications-detail-redirect/ immunity-passports-in-the-context-of-covid-19

4. Alizargar J. (2020). Risk of reactivation or re-infection of novel coronavirus (COVID-19) Journal of the Formosan Medical Association, 119(6), 1123.doi: 10.1016/ j.jfma.2020.04.013.

5. Parry, J. (2020). Covid-19: Hong Kong scientists report first confirmed case of re-infection. The BMJ, 370.doi: 10.1136/bmj.m3340.

6. Howard, J. (2020). Doctors find possible case of Covid19 reinfection in US. CNN news. Published on 29 August 2020. Link: https://edition.cnn.com/world/live-news/ coronavirus - pande mic- $08-29$ - 20 - in t $1 /$ h_5d1789a40f001d715a4ca461b4ae6257

7. Ecuador confirms first case of COVID-19 re-infection. CGTN.Published on 30 August 2020. Link: https:// news.cgtn.com/news/2020-08-30/Ecuador-confirmsfirst-case-of-COVID-19-reinfection-Tn8RnpNU40 / index.html 